\title{
Da geometria à álgebra: uma proposta de interpretação gráfica de retas com o GeoGebra \\ Raquel Marchetto $^{1}$ - IM/PPGEMAT/UFRGS - rmarche3@gmail.com
}

\section{Resumo}

Atualmente, a utilização de novas tecnologias em sala de aula vem se tornando cada vez mais necessária, uma vez que os alunos estão sedentos desse recurso para estarem preparados para a vida social e para o mundo do trabalho. O grande desafio do professor é tentar inserir essa nova metodologia de forma criativa e inovadora. Este artigo é um relato de experiência realizada com 16 alunos de uma turma de terceiro ano do Ensino Médio tendo como objetivo utilizar o software GeoGebra como recurso didático nas aulas de matemática para explanação acerca de conhecimentos sobre Geometria Analítica. O enfoque se deu especialmente no que diz respeito ao estudo de retas, visando à conversão do registro gráfico para o algébrico através da exploração de imagens criadas no software GeoGebra, tornando a aprendizagem significativa.

Palavras - chaves: GeoGebra, Geometria Analítica, retas.

\section{From Geometry to algebra: a proposal for a graphical interpretation of straight with the GeoGebra}

\begin{abstract}
Currently, the use of new technologies in the classroom is becoming increasingly necessary, once students are starved for this resource to be prepared for the social life and de world of work. The great challenge of the teacher is trying to insert this new methodology in a creative and innovative way. This article is a report of an experience realized with sixteen students in a class of third year high school aiming to use the GeoGebra software as a teaching tool in mathematics lessons for explanation about knowledge of Analytical Geometry. The approach was made especially with regard to the study of straight, aimed at converting the record to the algebraic graph by exploiting images created in GeoGebra software, making the learning meaningful.
\end{abstract}

Key - Words: GeoGebra, Analytic Geometry, straight.

\section{Introdução}

A constante procura de novas maneiras mais produtivas na área da Educação suscita a necessidade de se criar novas metodologias distintas das tradicionais a fim de se estabelecer uma nova relação entre professores e alunos. Devido ao processo de evolução das ciências e, consequentemente, das tecnologias que nos cerca, importantes passos já foram e estão sendo dados na busca de novos métodos de ensino de Matemática. Neste modelo atual da sociedade, "os recursos tecnológicos de informática na escola podem contribuir para a melhoria das condições no acesso à informação", como cita Pais (2002). Os Softwares Matemáticos atualmente ocupam um lugar de destaque no ensino e nos currículos de Matemática. De acordo com os $\mathrm{PCNs}^{2}$, as tecnologias em suas diferentes formas e usos, constituem um dos principais agentes de

\footnotetext{
1 Aluna Especial do PPGEMAT - UFRGS, Especialista em Ensino da Matemática, Professora da rede estadual de ensino.

${ }^{2}$ A sigla PCNs reporta-se aos Parâmetros Curriculares Nacionais que são referenciais de qualidade elaboradas pelo Governo Federal em 1996. Essas diretrizes são voltadas, sobretudo, para a estruturação e reestruturação dos currículos escolares de todo o Brasil. O objetivo principal dos PCNs é padronizar o ensino no país, estabelecendo pilares fundamentais para guiar a educação formal e a própria relação escola-sociedade no cotidiano.
} 
transformação da sociedade, pelas modificações que exercem nos meios de produção e por suas consequências no cotidiano das pessoas. A informática caracteriza o aprendizado como um processo de investigação, o que torna uma grande mudança de paradigma para a educação, com novos conceitos e estruturas a serem pensadas e trabalhadas.

O acesso à informática deve ser visto como um direito e, portanto, nas escolas públicas e particulares o estudante deve poder usufruir de uma educação que no momento atual inclua, no mínimo, uma "alfabetização tecnológica". Tal alfabetização deve ser vista não como um Curso de Informática, mas, sim, como um aprender a ler essa nova mídia. Assim, o computador deve estar inserido em atividades essenciais, tais como aprender a ler, escrever, compreender textos, entender gráficos, contar, desenvolver noções espaciais etc. E, nesse sentido, a informática na escola passa a ser parte da resposta a questões ligadas à cidadania. (BORBA e PENTEADO, 2001, p. 17)

A possibilidade de assumir a utilização de novas tecnologias no ensino da Matemática nos trazem novidades e situações de desafio acompanhadas de fatos que despertam curiosidades, perceptivas afetivas e cognitivas. São fatores extremamente motivadores que fazem da tecnologia um elemento de alto potencial educativo capaz de conduzir professores e, principalmente, os alunos, a um mundo caracterizado por uma lógica binária e "desafiá-los" a formular estratégias de resolução de problemas, formular pensamento estratégico e a capacidade de tomar decisões de fundamental importância para o desenvolvimento de atividades no âmbito da Educação Matemática.

Esse impacto da tecnologia, cujo instrumento mais relevante é hoje o computador, exigirá do ensino de Matemática um redirecionamento sob uma perspectiva curricular que favoreça o desenvolvimento de habilidades e procedimentos com os quais o indivíduo possa se reconhecer e se orientar nesse mundo do conhecimento em constante movimento. (PCNs de Matemática, p. 41).

Os programas computacionais (softwares) educativos, em especial o GeoGebra, apresentam inúmeras capacidades funcionais e propriedades que podem ser reconhecidas e aproveitadas por professores e alunos para obter resultados eficientes no processo de ensino e aprendizagem de Matemática. A elaboração da atividade, a aplicação e discussão de resultados junto a processos que formam a integração da teoria e a prática são os elementos constitutivos da atividade de ensino.

Conforme Borba e Penteado (2001), a informática é um tema de grande discussão que busca sua contínua inserção no ensino da Matemática. Porém, aliar recursos computacionais a conteúdos matemáticos requer preparação e investigação na escolha de softwares adequados e viáveis que possam auxiliar no exercício, possibilitando tanto aos alunos, como aos professores o aprimoramento de seus conhecimentos.

Os softwares educacionais estão sendo introduzidos de forma cada vez mais frequente e rápida em todos os níveis de educação. Sua utilização no ensino da matemática possui pontos positivos, mas também pontos negativos e, portanto, é preciso que os educadores sejam críticos e objetivos ao utilizarem esta ferramenta em aula. Segundo Gravina (1996), pode-se dizer que os ambientes informatizados apresentam-se como simples ferramentas de suporte ao processo de ensino e aprendizagem. 
Nessa perspectiva, este artigo tem como objetivo apresentar uma sequência de atividades realizadas com alunos de uma turma de terceiro ano do Ensino Médio utilizando o software GeoGebra e a representação gráfica e algébrica de retas. Os alunos precisaram de conhecimentos de Geometria Analítica de plano cartesiano e de equações de retas. O objetivo desta proposta é despertar no aluno o interesse pelo estudo dos conteúdos citados, para que possam perceber a importância da representação geométrica e algébrica no estudo da Geometria Analítica bem como lhes possibilitar possíveis identificações de conhecimentos prévios para o estudo destes conteúdos. A aprendizagem significativa de um conceito esta ligada à capacidade que o aluno terá de buscar as diferenciações e semelhanças ou regularidades entre o novo conhecimento e o conhecimento já existente. Ausubel (1982) diz que é indispensável para que haja uma aprendizagem significativa, que os alunos se predisponham a aprender significativamente.

\section{As possibilidades do software GeoGebra}

Criado em 2001 por Markus Hohenwarter, o GeoGebra é um software gratuito de matemática dinâmica desenvolvido para o ensino e aprendizagem da matemática nos vários níveis de ensino (do básico ao universitário). O GeoGebra reúne recursos de geometria, álgebra, tabelas, gráficos, probabilidade, estatística e cálculos simbólicos em um único ambiente. Assim, o GeoGebra tem a vantagem didática de apresentar, ao mesmo tempo, representações diferentes de um mesmo objeto que interagem entre si.

A sua tela de trabalho disponibiliza em linguagem clássica da geometria recursos para construção de figuras a partir das propriedades que as definem. O processo de construção é feito mediante escolhas primitivas que são encontradas nos diferentes menus - pontos, retas, círculos, retas paralelas, retas perpendiculares - e o software retorna a respectivas equivalências algébricas (coordenadas, equações, etc.).

Os programas que fazem "traduções" entre diferentes sistemas de representação apresentam-se como potentes recursos pedagógicos, principalmente porque o aluno pode concentrar-se em interpretar o efeito de suas ações frente às diferentes representações, até de forma simultânea, e não em aspectos relativos à transição de um sistema a outro, atividade que geralmente demanda tempo. (GRAVINA e SANTAROSA, 1999).

Quando trabalhado com geometria no GeoGebra, pode-se utilizar construções clássicas como reta perpendicular, ponto médio, mediatriz, bissetriz, etc. A partir de uma construção é possível aplicar movimento a seus elementos, sendo preservadas as propriedades geométricas impostas à figura. Para o estudo das funções e das equações da geometria analítica (retas, cônicas,...), existe a possibilidade de trabalhar com coordenadas cartesianas. Os recursos disponibilizados no GeoGebra facilitam a exploração algébrica e gráfica, de forma simultânea, o que ajuda o aluno a entender, por exemplo, o conceito de função, e o significado geométrico do conjunto - solução de uma equação.

Segundo o idealizador do software, a característica mais destacável do GeoGebra é a percepção dupla dos objetos: cada expressão na janela de Álgebra corresponde a um objeto na Zona de Gráficos e vice-versa.

Por um lado o GeoGebra possui todas as ferramentas tradicionais de um software de geometria dinâmica: pontos, segmentos, retas e seções cônicas. Por outro lado, equações e coordenadas podem ser inseridas diretamente. Assim, o GeoGebra tem a vantagem didática de apresentar, ao mesmo tempo, duas representações diferentes de um mesmo objeto que interagem entre si: sua representação geométrica e sua 
representação algébrica sendo então mais uma ferramenta que pode oferecer a oportunidade de dinamizar e consolidar o trabalho pedagógico em matemática.

\section{O estudo da Geometria Analítica}

De acordo com Santos (2008), a geometria analítica destaca-se por explorar a relação entre a geometria e a álgebra, proporcionando uma visão e a compreensão do espaço de maneira mais elaborada mobilizando formas e raciocínios singulares em relação aos utilizados na Geometria Euclidiana. Segundo os PCNs+ a geometria analítica permite o entendimento de figuras geométricas via equações, e o entendimento de equações, via figuras geométricas.

A Geometria Analítica, também denominada de coordenadas geométricas, se baseia nos estudos da Geometria através da utilização da Álgebra. Os estudos iniciais estão ligados ao matemático francês René Descartes (1596 -1650), criador do sistema de coordenadas cartesianas que relacionou os estudos da Álgebra com a Geometria, criou princípios matemáticos capazes de analisar por métodos geométricos as propriedades do ponto, da reta e da circunferência, determinando distâncias entre eles, localização e pontos de coordenadas.

Uma característica importante se apresenta na definição de formas geométricas de modo numérico, extraindo dados informativos da representação. Descartes utilizou o Plano Cartesiano no intuito de representar planos, retas, curvas e círculos através de equações matemáticas. Surgindo no intuito de algebrizar a geometria, criando métodos que visam auxiliar a resolução de vários problemas no estudo da Geometria Analítica, as figuras geométricas têm suas propriedades analisadas e estudadas com base em cálculos algébricos. Esses conteúdos são inerentes às turmas de $2^{\mathrm{a}}$ ou $3^{\mathrm{a}}$ série do Ensino Médio, de acordo com as grades curriculares das instituições de ensino. É papel do professor especificar a importância desse estudo que por muitas vezes é esquecido ou deixado de lado por "falta de tempo".

A dualidade álgebra-geometria é a essência do estudo em geometria analítica, estando de acordo com o que ditam os PCNs+:

... mais importante do que memorizar diferentes equações para um mesmo ente geométrico, é necessário investir para garantir a compreensão do que a geometria analítica propõe.

Construir uma visão sistemática das diferentes linguagens e campos de estudo da Matemática, estabelecendo conexões entre eles. (BRASIL, 2002, p. 124 e 125).

Dentro da geometria analítica será abordada a equação geral da reta ${ }^{3}$, criando mecanismos capazes de auxiliar no ensino aprendizado de tal conteúdo. Pela geometria plana sabe-se que a reta é constituída de pontos colineares, isto é, alinhados. Além da representação pela geometria plana, a reta também pode ser explicada pela geometria espacial, partindo do pressuposto de que a mesma é formada por pontos alinhados, estes pontos no espaço possuem coordenadas x e y (plano cartesiano). O principal objetivo da

\footnotetext{
${ }^{3}$ Toda reta do plano cartesiano é gráfico de uma equação da forma $a x+b y+c=0$, em que $x$ e $y$ são variáveis e $a, b$ e $c$ são números reais, com $a \mathrm{e}^{b}$ não simultaneamente nulos. Reciprocamente, toda equação dessa forma representa uma reta do plano cartesiano. Essa equação é chamada de equação geral da reta.
} 
Geometria Analítica é criar uma equação que generaliza uma reta no espaço, isto pode ser feito utilizando o princípio do alinhamento de pontos propostos pelo determinante de uma matriz.

Essa proposta tem como objetivo tratar algebricamente as propriedades e os elementos geométricos. O aluno do ensino terá a oportunidade de conhecer essa forma de pensar que transforma problemas geométricos na resolução de equações. $\mathrm{O}$ discente deve perceber que um mesmo problema pode então ser abordado com diferentes instrumentos matemáticos de acordo com suas características. Mais importante do que memorizar diferentes equações para um mesmo ente geométrico, é necessário investigar para garantir a compreensão do que a geometria analítica propõe. Para isso, o trabalho com este tema pode ser centrado em estabelecer a correspondência entre as equações e seus gráficos e a resolução de problemas que exigem o estudo da posição relativa de pontos e retas, garantindo que os alunos aprendam a efetuar medições em situações reais com a precisão requerida ou estimando a margem de erro.

\section{Metodologia e desenvolvimento da proposta}

A proposta foi desenvolvida no Colégio Estadual Visconde de Bom Retiro numa turma de terceiro ano do Ensino Médio composta por 16 alunos, onde realizo atividades docentes como titular na disciplina de Matemática. Para o desenvolvimento das tarefas a turma foi dividida em cinco grupos, um quarteto que será denominado de Grupo 1, e 4 trios denominados de Grupo 2, Grupo 3, Grupo 4 e Grupo 5.

A aplicação e desenvolvimento das tarefas foram realizadas durante seis períodos de aula. Para desenvolver as atividades foi utilizado o software de Geometria Dinâmica, o Geogebra, em que, cada grupo de posse de material impresso, desenvolvia as atividades propostas, sendo auxiliados pelo professor. Após cada atividade o grupo fazia seus apontamentos e elaborava conclusões para que, em um segundo momento, houvesse a socialização das observações. A construção do exercício proposto tinha a finalidade de dirimir possíveis dúvidas e levantar novos questionamentos e observações.

Foram desenvolvidas 3 atividades que serão aqui discorridas e detalhadas considerando as possibilidades de resolução apresentadas pelos grupos. A atividade 1 foi realizada como via de exploração e entendimento da proposta para a realização das demais atividades. A tarefa consistia em encontrar as equações gerais das retas suporte do triângulo, criado no GeoGebra e representado na imagem projetada. Após encontrar as equações deveriam encontrar os pontos de intersecção das mesmas e reproduzir a imagem no GeoGebra utilizando as equações.

Na Figura 1, observa-se a reprodução do triângulo, construído pelo Grupo 1, e na Figura 2, o método utilizado pelo grupo para encontrar as equações gerais das retas. 
6

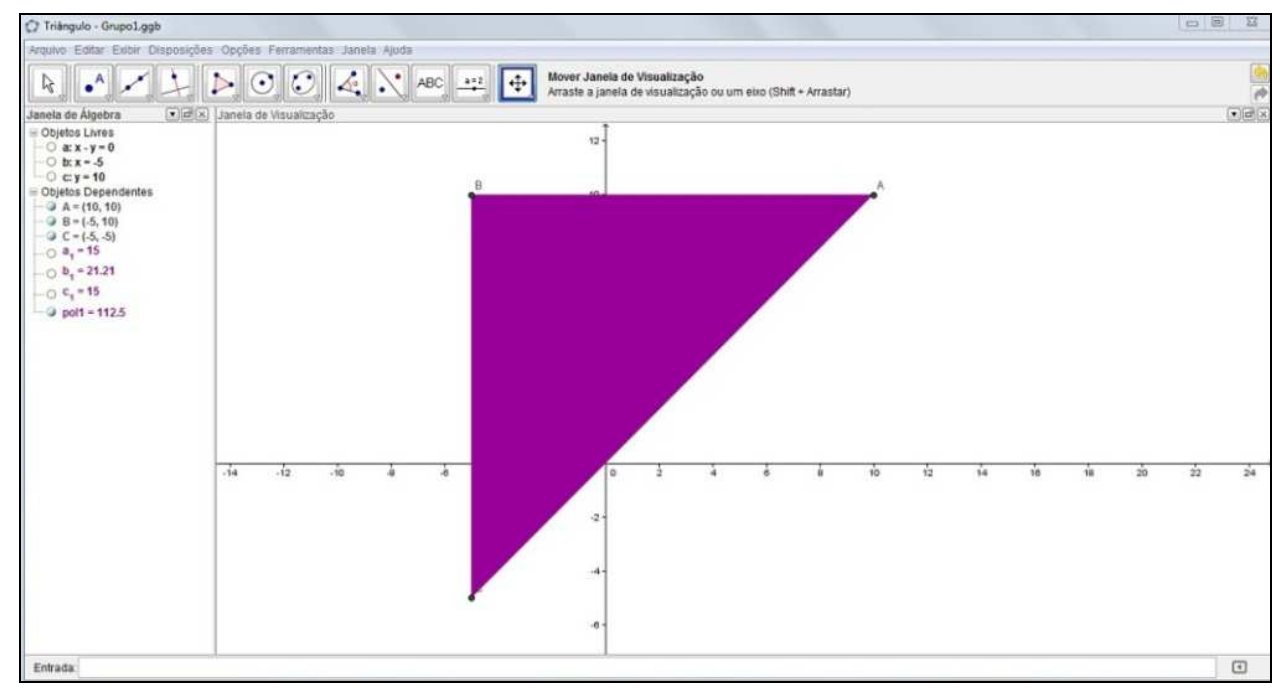

Figura 1 - Reprodução do triângulo, construído pelo Grupo 1

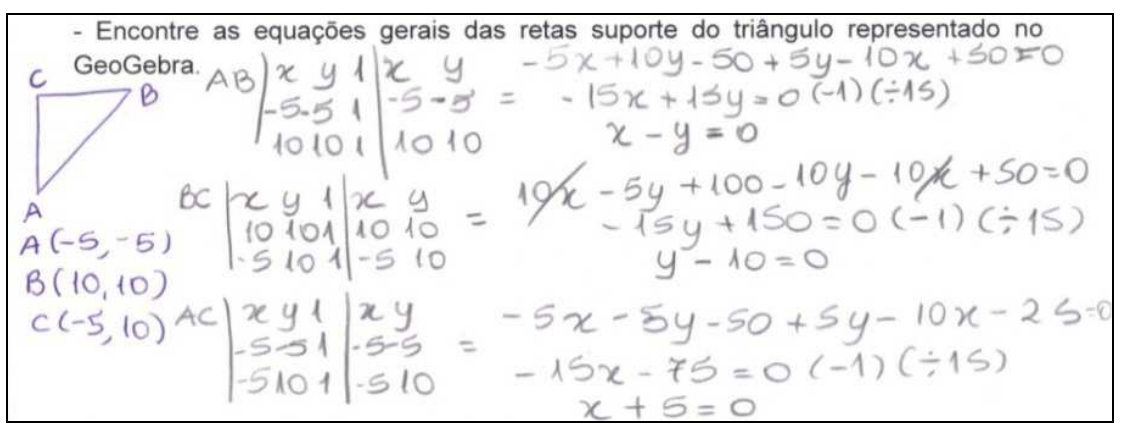

Figura 2 - Método utilizado pelo Grupo 1 para encontrar as equações gerais das retas

Do mesmo modo que o Grupo 1, os demais grupos também identificaram os vértices do triângulo como pontos e encontraram as equações utilizando o princípio do alinhamento de pontos propostos pelo determinante de uma matriz. Os grupos não se deram conta dos casos particulares de retas apresentados no triângulo, horizontal (paralela ao eixo x) e vertical (paralela ao eixo y), a constatação foi feita quando discutida a resolução no grande grupo. Segundo as orientações curriculares para o ensino médio o entendimento do significado de uma equação e de seu conjunto de soluções não é imediato, e isso é natural, pois esse significado não é explícito quando simplesmente se escreve uma equação.

Para encontrar os pontos de intersecção entre as retas os grupos utilizaram a resolução de sistemas e concluíram posteriormente que nem precisavam ter tido todo aquele "trabalho", pois os pontos eram os próprios vértices do triângulo. Na formação do triângulo foi utilizado o comando "polígono" no GeoGebra selecionando os vértices e escondidas as retas suporte para o aparecimento somente da figura. Com essa construção observou-se de que maneira os alunos fazem a interpretação das questões e como o computador pode auxiliar no processo de aprendizagem do conhecimento matemático. Os PCNs determinam para a Educação Matemática e os recursos tecnológicos, uma relação de reciprocidade. A Matemática deve servir para entender e se apropriar das tecnologias digitais assim como esta deve ser ferramenta para entender a Matemática. 
Com a compreensão e a discussão do processo na construção do triângulo foi proposta a atividade 2, foi projetada uma nova imagem (Figura 3), um barco construído com o GeoGebra.

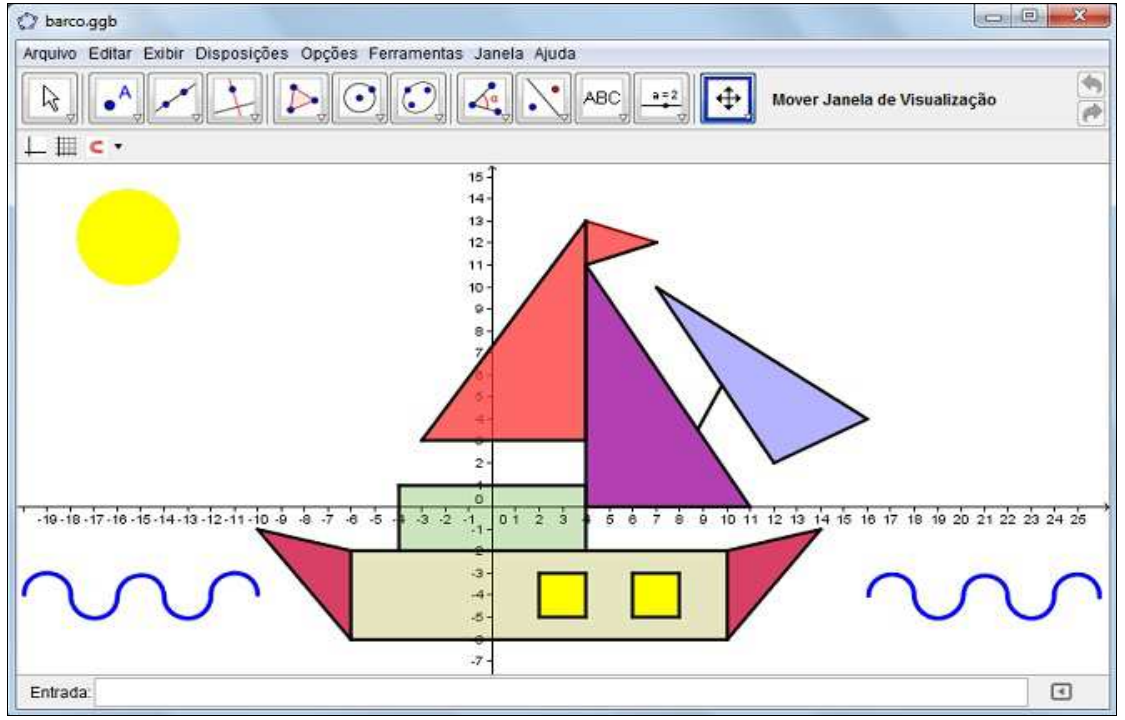

Figura 3 - Barco construído no GeoGebra

Nesta segunda atividade o desafio foi maior, pois os alunos tiveram que encontrar as 26 equações das retas suportes que estavam escondidas conforme mostrado na Figura 4.

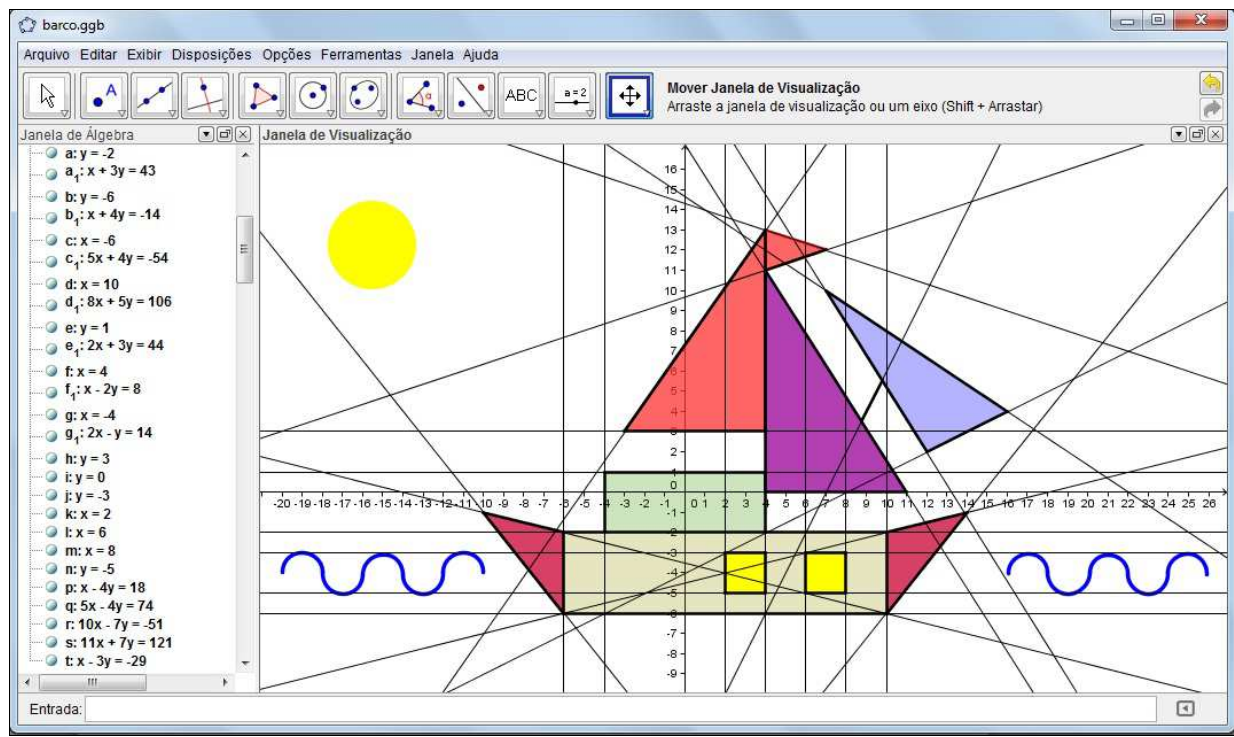

Figura 4 - Imagem do barco com as retas suporte

Já no início das discussões era possível escutar nos grupos "não vai ser muito difícil tem bastante retas na vertical e na horizontal". Começaram analisando as figuras que eram formadas por retas horizontais ou verticais e para facilitar a visualização da imagem, tendo os pontos bem identificados, os grupos resolveram pegar papel quadriculado e copiar o barco, como pode ser visto na Figura 5, a reprodução do Grupo 5 . 


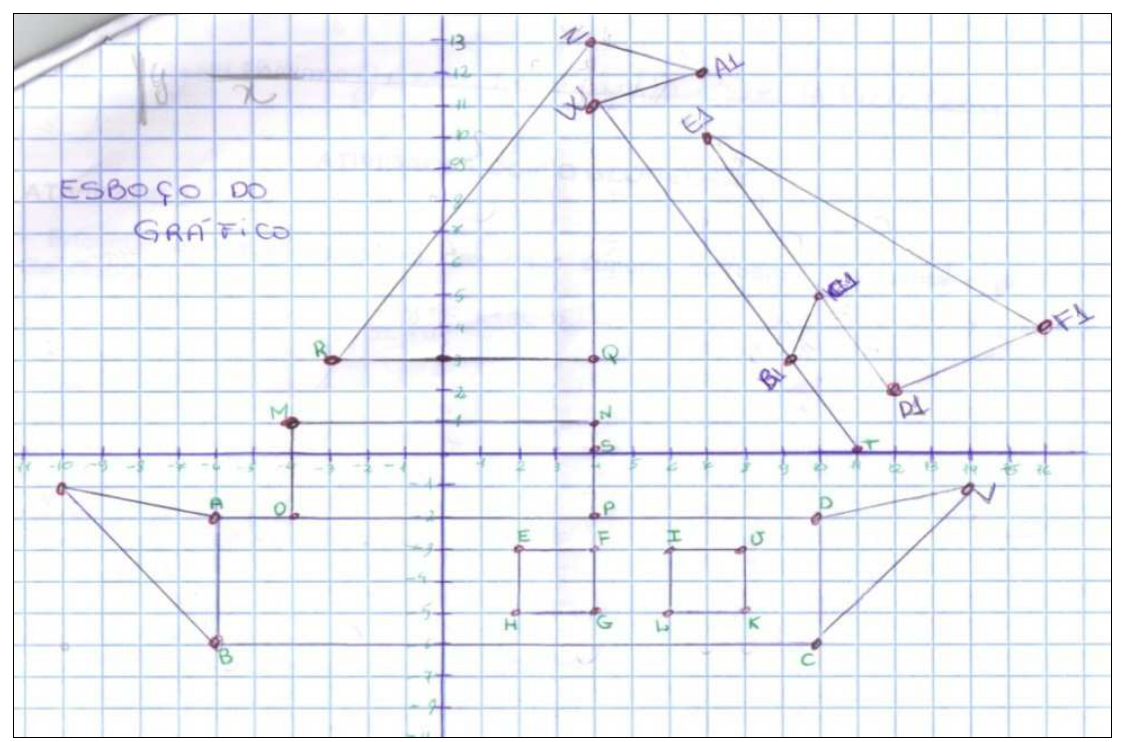

Figura 5 - Reprodução do barco em papel quadriculado do Grupo 5

Em dois períodos os grupos encontraram as equações das retas utilizando a condição de alinhamento de pontos e reproduziram o barco no GeoGebra, a cada equação de reta que encontravam já iam inserindo na caixa de entrada para verificar se estava correta a sua posição geométrica para a reconstrução do barco. Segundo as orientações curriculares para o ensino médio o trabalho com a geometria analítica permite a articulação entre geometria e a álgebra. Para que essa articulação seja significativa para o aluno, o professor deve trabalhar as duas vias: o entendimento de figuras geométricas via equações, e o entendimento de equações via figuras geométricas.

De acordo com relatos e discussões após a atividade a maior dificuldade encontrada pelos grupos foi a visualização dos pontos da projeção do barco por isso sentiram a necessidade de reproduzir a imagem em papel quadriculado. Isso demonstra o desenvolvimento de autonomia na sala de aula onde os alunos tomaram decisões racionais sobre o planejamento de seu trabalho, partindo daquilo que já sabiam. Ausubel (1982) considera que a assimilação de conhecimentos ocorre sempre que uma nova informação interage com outra existente na estrutura cognitiva, mas não com ela como um todo; o processo contínuo da aprendizagem significativa acontece apenas com a integração de conceitos relevantes.

$\mathrm{Na}$ atividade 3, foi proposta uma construção elaborada pelos próprios grupos a partir de uma imagem de inspiração pesquisada pelos mesmos. Os grupos tiveram que reproduzir a imagem selecionada utilizando equações de retas, como visto nas propostas anteriores, para a construção dos polígonos. Através dessa proposta os alunos desenvolvem habilidades de visualização, de desenho, de argumentação lógica e de aplicação na busca de uma solução. É oportunizado o conhecimento da forma de pensar que transforma problemas geométricos na resolução de equações, aprendendo a efetuar medições em situações reais, compondo e decompondo figuras, construindo uma visão sistemática das diferentes linguagens e campos do estudo da Matemática, estabelecendo conexões entre eles.

Encontra-se na Figura 6, a imagem de inspiração escolhida pelo Grupo 2 e, na Figura 7, a reprodução feita pelo grupo utilizando o GeoGebra. 


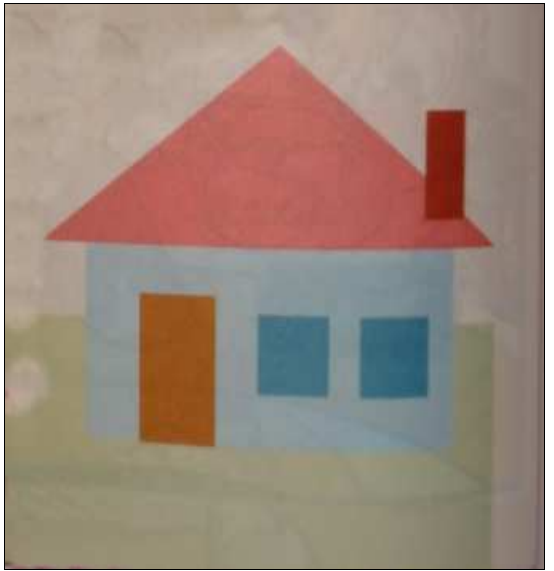

Figura 6 - Imagem de inspiração

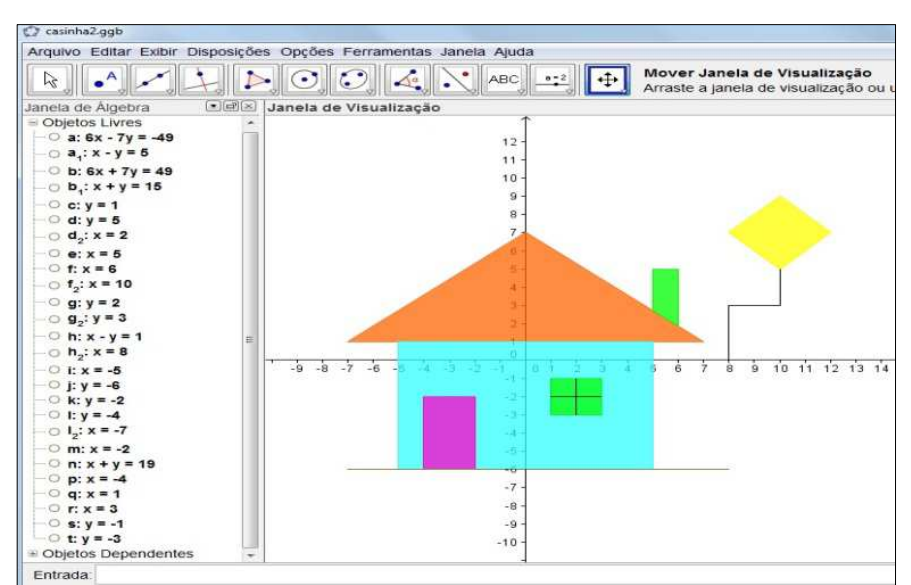

Figura 7 - Reprodução da imagem do Grupo 2

O grupo resolver incrementar um pouco a imagem adicionando uma pıpa ao fundo, pois alegaram que "a imagem estava muito simples daí resolvemos desenhar atrás da casa uma pipa para ficar mais bonito". A intenção da proposta não era reprodução fiel à imagem de inspiração, a mesma servia somente como uma base para as construções. O objetivo principal era o de identificar se os alunos conseguiam relacionar equações de retas com as posições das retas suportes da imagem. O Grupo 2 realizou a construção a partir das retas que na Figura 7 estão como objetos ocultos, mas aparecem na janela de álgebra no lado esquerdo.

Na Figura 8 e na Figura 9, estão ilustradas as construções dos grupos 3 e 4 sem ocultar as retas suporte da imagem para mostrar o entendimento da proposta da atividade realizada.

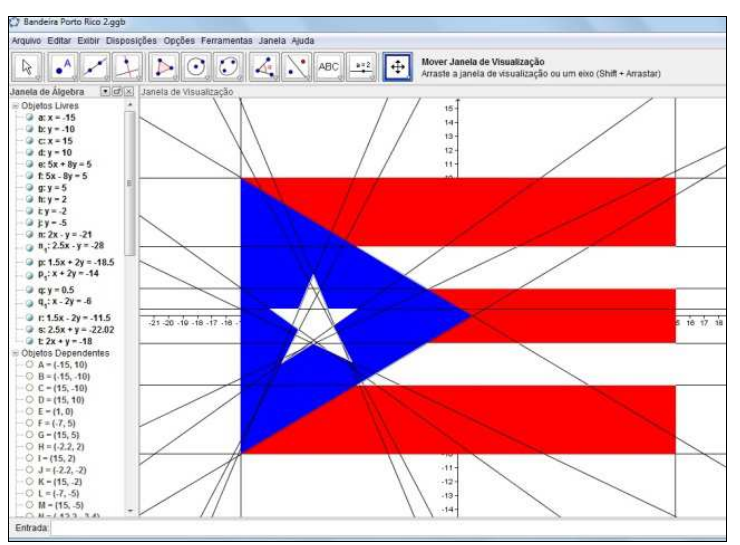

Figura 8 - Construção do Grupo 3

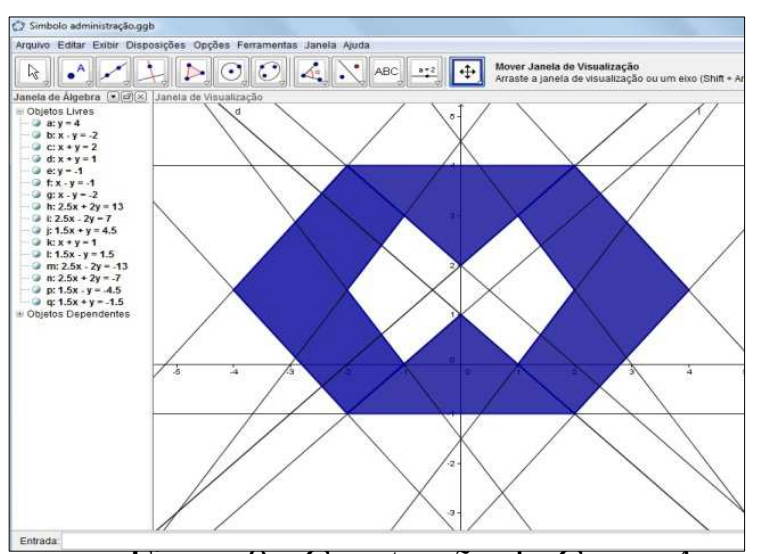

Figura 9 - Construção do Grupo 4

O Grupo 3 salientou a dificuldade em fazer a construção da estrela devido o formato das suas pontas, "a estrela não dava certo, até que conseguimos, a gente refez várias vezes, mas ainda ficou um pouco torta".

No encerramento das atividades foi feita a apresentação das construções dos grupos para toda a turma.

\section{Considerações finais}

Este artigo teve como propósito apresentar os resultados da proposta realizada com os alunos do $3^{\circ}$ ano do Ensino Médio em uma escola da rede estadual. Neste 
trabalho apresentam-se os resultados das atividades realizadas cujo objetivo era o tratamento algébrico de figuras geométricas.

Percebeu-se que os grupos conseguiram fazer as atividades com o uso de estratégias, como reproduzir em papel quadriculado as imagens para posterior construção discutindo a localização de pontos para a construção das retas. O uso do software GeoGebra como uma estratégia didático-pedagógica contribuiu para a aprendizagem destes alunos. Os grupos destacaram a possibilidade de testar as equações de modo dinâmico e rápido. Algumas dificuldades que surgiram no tratamento algébrico foram nos cálculos essenciais na resolução do determinante para encontrar as equações, e no geométrico a identificação dos pontos de intersecção entre as retas para a construção dos polígonos. Os avanços dos alunos foram claramente observados quando todos os grupos conseguiram realizar sua construção proposta pela atividade 3 .

$\mathrm{Na}$ relação entre o uso de tecnologias e o ensino da Matemática o que se desenvolve com a escolha de softwares educacionais é a possibilidade de construir, deformar, reconstruir e modificar as construções feitas na tela do computador permitindo testar propriedades, resultados e suposições. Essas interações geraram as discussões e por consequência o aprofundamento no conteúdo. Acredita-se que este contexto leva a apontar o software educacional GeoGebra como um recurso metodológico do presente e do futuro, ressaltando também que a escola tem que criar as interações e condições diversas de linguagem.

Utilizando a tecnologia disponível aliada ao conhecimento matemático o computador torna-se um facilitador no processo, observou-se durante as atividades desenvolvidas, que a teoria e a prática se complementam, tornando o processo mais dinâmico e interativo, consequentemente, obtendo uma educação de melhor qualidade. A detecção da capacidade criativa dos alunos, o entusiástico engajamento dos alunos nos trabalhos, produzindo discussões e trocas de ideias revelam uma intensa atividade intelectual.

Analisando a aplicação da proposta verifica-se que não se deve descartar na abordagem da Geometria Analítica o estudo das propriedades geométricas de uma figura com base em uma equação, e o estudo dos pares ordenados de números ( $\mathrm{x}, \mathrm{y})$ que são soluções de uma equação, por meio das propriedades de uma figura geométrica. Conceitos a serem aprendidos precisam possuir significado para que o aprendiz possa registrar a informação a ser aprendida de forma mais precisa e objetiva relacionando, assim, o que aprendeu com o contexto ao seu redor, tornando a aprendizagem significativa, plena de sentido.

\section{Referências Bibliográficas}

AUSUBEL, D. P. A aprendizagem significativa: a teoria de David Ausubel. São Paulo: Moraes, 1982.

BICUDO, Maria Aparecida Viggiani. Pesquisa em Educação Matemática: Concepções e Perspectivas. In: BORBA, Marcelo de Carvalho; PENTEADO, Miriam Godoy. Pesquisa em Educação Matemática: Concepções e Perspectivas. São Paulo: UNESP, 1999.

BORBA, Marcelo de Carvalho; PENTEADO, Miriam Godoy. Informática e Educação Matemática. Belo Horizonte: Autêntica, 2001.

BORTOLOSSI, José Humberto. GeoGebra. Rio de Janeiro: Instituto de Matemática e Estatística da Universidade Federal Fluminense, 2010. Disponível em: 
<http://www.professores.uff.br/hjbortol/geogebra/geogebra.overview.html>. Acesso em 16 de outubro de 2012.

BRASIL. PCNs (Parâmetros Curriculares Nacionais). Ciências da natureza, matemática e suas tecnologias. Brasília: Ministério da Educação, Secretaria de Educação Básica, 2006. (Orientações curriculares para o ensino médio; volume 2).

BRASIL. PCNs+ (Ensino Médio). Orientações Educacionais Complementares aos Parâmetros Curriculares Nacionais. Ciências da natureza, matemática e suas tecnologias. Brasília: Ministério da Educação, Secretaria de Educação Básica, 2002.

GRAVINA, M. A.. Geometria Dinâmica: Uma Nova Visão para o Aprendizado da Geometria. In: Anais do VII Congresso Brasileiro de Informática na Educação. Belo Horizonte, 1996.

GRAVINA, M. A.; SANTAROSA, L. M. C. A aprendizagem da matemática em ambientes informatizados. INFORMÁTICA NA EDUCAÇÃO: teoria \& prática. Porto Alegre, v. 1, n. 2, 1999.

PAIS, Luiz Carlos. Educação Escolar e as Tecnologias da Informática. Belo Horizonte: Autêntica, 2002.

SANTOS, Ricardo de S. Tecnologias Digitais na Sala de Aula para Aprendizagem de Conceitos de Geometria Analítica: Manipulações no Software Grafequation. Dissertação de Mestrado. Universidade Federal do Rio Grande do Sul, Porto Alegre, 2008.

em: <http://www.lume.ufrgs.br/bitstream/handle/10183/15880/000692687.pdf?sequence=1> Acesso em 09 de outubro de 2012. 